\title{
Antiproliferative activity of monastrol in human adenocarcinoma (MCF-7) and non-tumor (HB4a) breast cells
}

\author{
Lilian Areal Marques ${ }^{1} \cdot$ Simone Cristine Semprebon ${ }^{1} \cdot$ Andressa Megumi Niwa $^{1}$. \\ Gláucia Fernanda Rocha D'Epiro ${ }^{1}$. Daniele Sartori ${ }^{1}$ - Ângelo de Fátima ${ }^{2}$. \\ Lúcia Regina Ribeiro $^{3}$. Mário Sérgio Mantovani ${ }^{1}$
}

Received: 14 March 2016/Accepted: 22 August 2016/Published online: 3 September 2016

(C) Springer-Verlag Berlin Heidelberg 2016

\begin{abstract}
Monastrol is an allosteric inhibitor of the mitotic kinesin Eg5 that exhibits an antiproliferative effect against several cell lines. We investigated the antiproliferative effect of monastrol on human breast adenocarcinoma cells (MCF-7) and mammary epithelial cells (HB4a, non-tumoral). Monastrol treatment decreased cell viability only in MCF-7 tumor cells. Real-time cell growth kinetic analysis showed a decrease in the proliferation of MCF-7 cells exposed to monastrol, while in the HB4a cells, only a concentration of $100 \mu \mathrm{M}$ was able to induce this effect. In a cell cycle analysis, exposure of MCF-7 cells to monastrol led to an increased population of cells in both the G1 and G2/M phases. In HB4a cells, the proportion of cells in the G2/M phase was increased. Monastrol led to an increased mitotic index in both cell lines. Monastrol was not able to induce cell death by apoptosis in any of the cell lines studied. Gene expression analysis was performed to measure the mRNA levels of cell cycle genes, DNA damage indicator gene, and apoptotic related genes. Treatment with monastrol induced in MCF-7 cells a 5-fold increase in the mRNA levels of the CDKN1A gene, an
\end{abstract}

Electronic supplementary material The online version of this article (doi:10.1007/s00210-016-1292-9) contains supplementary material, which is available to authorized users.

Lilian Areal Marques

lilian.areal.marques@gmail.com

1 Departamento de Biologia Geral, Universidade Estadual de Londrina, Rodovia Celso Garcia CID, PR 445, Km 380, Caixa Postal 10011, Londrina, Paraná CEP: 86057-970, Brazil

2 Departamento de Química, Universidade Federal de Minas Gerais, Belo Horizonte, Minas Gerais, Brazil

3 Departamento de Patologia, Universidade Estadual Paulista Júlio de Mesquita Filho, Botucatu, São Paulo, Brazil inhibitor of CDKs related with cell cycle arrest in response a stress stimulus, and a 2-fold decrease in CDKN1C mRNA levels in HB4a cells. These results provide evidence that monastrol has a greater antiproliferative effect on MCF-7 tumor cells compared with non-tumor HB4a cells; however, no selective is observed.

Keywords Monastrol $\cdot \mathrm{MCF}-7 \cdot \mathrm{HB} 4 \mathrm{a} \cdot \mathrm{Kinesin} 5$. CDKN1A

\section{Introduction}

Cancer is a genetic disease resulting from the accumulation of mutations that lead to maintenance of signaling proliferation, insensitivity to growth suppression, resistance to cell death, replicative immortality, induction of angiogenesis, invasion of adjacent tissues, ability to reprogram the cell metabolism, and evasion of the immune system (Hanahan and Weinberg 2000, 2011). In recent decades, cancer has become a global health problem, and breast cancer is the most common among women, just lose for skin non-melanoma, and leads to higher mortality in this group (Ferlay et al. 2015).

For many years, antimitotic drugs that target microtubules have been used for anticancer chemotherapy. However, microtubules are also essential for other cellular processes, such as transport of subcellular components and neurotransmitters (Harrison et al. 2009). Therefore, compounds that interfere with microtubule dynamics cause adverse effects, such as neutropenia and neurotoxicity (Huszar et al. 2009; Rowinsky et al. 1993; Tuxen and Hansen 1994). Despite the great progress of cancer treatment with these agents, it is necessary to develop compounds that have new targets and mechanisms of action to reduce side effects. 
Monastrol is a novel low molecular weight cell-permeable molecule, and studies have demonstrated the potential of this molecule for interfering with the formation of the mitotic spindle and cell cycle progression (Kapoor et al. 2000; Mayer et al. 1999). Monastrol was reported to be an allosteric inhibitor of the mitotic kinesin Eg5, the Xenopus laevis homolog of human kinesin spindle protein (KSP) (Chin and Herbst 2006; Maliga and Mitchison 2006), a protein required in early mitosis for the separation of centrosomes and mitotic spindle formation (Blangy et al. 1995; Enos and Morris 1990; Ferenz et al. 2010). This protein is overexpressed in tumor tissues, including breast solid tumors, colon, lung, ovary, rectum, and uterus (Koller et al. 2006; Le Guellec et al. 1991; Sakowicz et al. 2004), compared with adjacent non-tumor tissues. Besides, studies have shown that monastrol does not cause the neurotoxicity known to other chemotherapies in use, and in some cases it has fewer deleterious effects than conventional chemotherapy (Yoon et al. 2005), and other studies find a positive effect of monastrol (Haque et al. 2004; Lin et al. 2011; Xu et al. 2015).

The antiproliferative activity of monastrol has been related (Chin and Herbst 2006; Kaur et al. 2010; Leizerman et al. 2004; Russowsky et al. 2006; Vijapurkar et al. 2007); however, the role of monastrol in tumor cells compared with nontumor cells is poorly known. In this context, the aim of this study was to evaluate the antiproliferative mechanisms of monastrol in a breast adenocarcinoma cell line (MCF-7) and non-tumor mammary epithelial cells (HB4a). The antiproliferative activity and the ability of this molecule to interfere with the cell cycle and induce cell death were evaluated by cytometry and morphological assays. Moreover, the gene expression of cell cycle components, such as cyclins, inhibitors of CDK, phosphatases, and the kinesin EG5, as well as genes involved in apoptosis and DNA damage response were evaluated.

\section{Materials and methods}

\section{Cell culture and monastrol}

The human breast adenocarcinoma MCF-7 cells were acquired from the Cell Bank of Rio de Janeiro and the nontumor human breast HB4a cells were kindly provided by A. C. Camargo Cancer Hospital (São Paulo, SP). The cells were grown in DMEM (Gibco) supplemented with $10 \%$ fetal bovine serum (FBS) (Gibco) and $1 \%$ penicillin/streptomycin (Gibco) at $37^{\circ} \mathrm{C}$ and $5 \% \mathrm{CO}_{2}$. The HB4a cells were supplemented with insulin (Gibco) and hydrocortisone (Nostra Pharma), both at a final concentration of $5 \mu \mathrm{g} / \mathrm{mL}$. The cell cycle under these conditions is approximately $24 \mathrm{~h}$.

Monastrol was synthesized in the Universidade Federal de Minas Gerais and provided by Ph.D Ângelo de Fátima.
Monastrol was dissolved in dimethyl sulfoxide (DMSO) (Acros Organics) and diluted in Dulbecco's modified Eagle's medium (DMEM) (Gibco-Life Technologies, Carlsbad, CA, USA), where the concentration of DMSO did not exceed $0.5 \%$ in culture.

\section{MTT cytotoxicity assay}

The cytotoxicity assay was performed with MTT (3-(4,5-dimethylthiazol-2-yl)-2,5-diphenyltetrazoliumbromide) (Invitrogen-Life Technologies) in accordance with the protocol described by Mosmann (1983), with some modifications. Cells were seeded in 96 -well culture plates $\left(5 \times 10^{3}\right.$ cells/well $)$ and incubated for $24 \mathrm{~h}$ for stabilization. After this period, the following treatments were administered for 24 and $48 \mathrm{~h}$ : vehicle control (0.5\% DMSO); $1 \mu \mathrm{M}$ doxorubicin (Adriblastina ${ }^{\circledR}$; Pharmacia), and monastrol at 5, 25, 50, 75, and $100 \mu \mathrm{M}$. After each time of treatment, the medium was withdrawn, serum-free media containing $0.5 \mathrm{mg} / \mathrm{mL}$ MTT salt was added and incubated for $4 \mathrm{~h}$, and formazan crystal products were diluted. The absorbance at $540 \mathrm{~nm}$ was converted to a percentage of surviving cells using the following formula: $\%$ viability $=\left(A_{\text {test }}-A_{\text {white }}\right) /\left(A_{\text {control }}-A_{\text {white }}\right) \times 100$, where $A$ equals absorbance average. The assay was performed in triplicate in three independent experiments.

\section{Real-time cell growth kinetics}

The xCELLigence-real-time cell analyzer (RTCA) system (Roche Applied Science, Germany) was used to monitor the dynamics of cell proliferation using the electric impedance. The experiment was designed according to the manufacturer's recommendations. The cells were seeded at the optimal concentration as determined by a previous titration experiment (6250 cells/well for MCF-7 cells and 3125 cells/well for HB4a cells). After $24 \mathrm{~h}$ of stabilization, the cells were treated with $5,25,50,75$, and $100 \mu \mathrm{M}$ of monastrol and $1 \mu \mathrm{M}$ doxorubicin for up to $96 \mathrm{~h}$. The impedance was monitored every $30 \mathrm{~min}$ and the experiment was conducted in triplicate.

\section{Apoptosis in situ and mitotic index}

MCF-7 and HB4a cells $\left(1.25 \times 10^{5}\right.$ cells/well $)$ were seeded in a six-well microplate and incubated for stabilization. After, the cells were exposed to DMSO $0.5 \%$, camptothecin $(3 \mu \mathrm{M})$, demecolcine solution $(26.9 \mathrm{nM})$, and 25 or $50 \mu \mathrm{M}$ monastrol for 24 and $48 \mathrm{~h}$. At the end of each treatment period, Hoechst $33342(5 \mu \mathrm{g} / \mathrm{mL}$; Sigma-Aldrich) was added for $15 \mathrm{~min}$ at $37{ }^{\circ} \mathrm{C}$ in the dark. To view and analyze the cells, the inverted fluorescence microscope, FLoid ${ }^{\circledR}$ Cell Imaging Station (Life technologies), was used at increased $\times 460$ magnification (Blue filter 390/40 nm excitation and 446/33 nm emission). Three biological experiments were performed, 500 cells per 
treatment were analyzed, and the values were expressed as a percentage of the total number of cells analyzed. Hoechst 33342 staining was performed to visualize morphologic characteristics of apoptosis, including nuclear condensation and the formation of apoptotic bodies, and cells in mitotic division with stained chromosomes in mitosis phase of the cell cycle.

\section{Cell cycle analysis}

MCF-7 and HB4a cells $\left(1.25 \times 10^{5}\right.$ cells/well $)$ were seeded in a six-well microplate and after $24 \mathrm{~h}$ of stabilization treated with DMSO $0.5 \%$, camptothecin $(3 \mu \mathrm{M})$ (Acros Organics), and 25 or $50 \mu \mathrm{M}$ monastrol. At the end of the treatments (24 and $48 \mathrm{~h}$ ), the cells were detached using Accutase (StemPro Accutase Cell Dissociation Reagent; Life Technologies), centrifuged (2000 rpm for $5 \mathrm{~min}$ ) and cold PBS was added. RNAse (Life Technologies) $(0.1 \mathrm{mg} / \mathrm{mL})$ was added and incubated for $30 \mathrm{~min}$ at $37{ }^{\circ} \mathrm{C}$, followed by staining with hypothonic fluorochrome solution (HFS) (PI $50 \mu \mathrm{g} / \mathrm{mL}$, sodium citrate $0.1 \%$, and Triton X-100 $0.1 \%$ ) for 30 min on ice in the dark (Savio et al. 2014) before flow cytometric analysis (Accuri C6; BD Pharmingen ${ }^{\mathrm{TM}}$ ). For each sample, 10,000 events were analyzed in three independent experiments.

\section{Annexin $V$ analysis of apoptosis}

The apoptosis analysis was performed using the Annexin V/PE Apoptosis Detection Kit (BD Pharmingen) for MCF-7 cells and the Annexin V/FITC Apoptosis Detection Kit (BD Pharmingen) for HB4a cells, and both cell lines were analyzed in the Accuri C6 cytometer (BD Pharmingen ${ }^{\mathrm{TM}}$ ).

MCF-7 and HB4a cells $\left(1.25 \times 10^{5}\right.$ cells/well $)$ were seeded in a six-well microplate, and after $24 \mathrm{~h}$ of stabilization, they were treated with DMSO $0.5 \%$, camptothecin $(3 \mu \mathrm{M})$, and 25 or $50 \mu \mathrm{M}$ monastrol for $24 \mathrm{~h}$. At the end of the treatment, the medium was removed and the cells were washed with cold PBS before the addition of Accutase (Life Technologies) for detachment. The cellular suspension was centrifuged (1000 rpm, $5 \mathrm{~min}$ ), the supernatant was discarded, and the pellet was resuspended in the manufacturer's buffer and stained with Annexin V/FITC and fluorochrome PI (BD Pharmingen ${ }^{\mathrm{TM}}$ 1:100)/Annexin V/PE and 7-AAD (BD Pharmingen ${ }^{\mathrm{TM}} 1: 100$ ) at room temperature protected from light for $15 \mathrm{~min}$. Three independent experiments were performed, and 10,000 events per treatment were analyzed.

\section{Quantitative reverse transcription PCR (RT-qPCR)}

MCF-7 and HB4a cells $\left(1.25 \times 10^{5}\right.$ cells/well $)$ were seeded in a six-well microplate and after $24 \mathrm{~h}$ of stabilization treated with DMSO $0.5 \%$ and $50 \mu \mathrm{M}$ monastrol for $24 \mathrm{~h}$. According to the manufacturer's instructions, total RNA was extracted using the RNeasy mini kit (Qiagen). RNA integrity was confirmed on an agarose gel $1 \%$ (28S and 18S rRNA pattern of bands), and concentration and purity $\left(A_{260} / A_{280}\right)$ were determined using a NanoDrop ${ }^{\circledR} 2000$ (ThermoScientific). Complementary DNA (cDNA) was synthesized according to the M-MLV protocol, using $40 \mathrm{U}$ of reverse transcriptase M-MLV (Invitrogen), $2.5 \mathrm{nM}$ dNTP mix, $10 \mathrm{pmol} / \mu \mathrm{L}$ oligo(dT) primer, RNAse out, and $500 \mathrm{ng}$ of total RNA. Real-time polymerase chain reactions were performed in the CFX96 ${ }^{\mathrm{TM}}$ Real-Time system (Bio-Rad) using SYBR Green (SsoAdvanced ${ }^{\mathrm{TM}}$ SYBR Green supermixBIORAD) in a total of $11 \mu \mathrm{L}$ of reaction mix $(5 \mu \mathrm{L}$ of cDNA $50 \mathrm{ng}, 5 \mu \mathrm{L}$ SYBR Green, and $1 \mu \mathrm{L}$ of each specific gene primer (10 pmol)). Conditions for the PCR reaction were as follows: $50{ }^{\circ} \mathrm{C}$ for $2 \mathrm{~min}, 95{ }^{\circ} \mathrm{C}$ for $2 \mathrm{~min}, 45$ cycles of denaturation (at $95^{\circ} \mathrm{C}$ for $15 \mathrm{~s}$ ), annealing (at $60^{\circ} \mathrm{C}$ for $15 \mathrm{~s}$ ), and extension (at $72{ }^{\circ} \mathrm{C}$ for $30 \mathrm{~s}$ ) per cycle. Melting curves $\left(55-95{ }^{\circ} \mathrm{C}\right.$ ready every $0.5{ }^{\circ} \mathrm{C}$ ) for each PCR reaction were generated to ensure the purity of the amplification product. To determine the cell cycle stage, mRNA levels of the following genes were determined: cyclin A2 (CCNA2), cyclin B1 (CCNB1), cyclin D1 (CCND1), and cyclin E1 (CCNE1); inhibitors of CDK p $21^{\mathrm{Cip} / \text { Waf1/Sdi1 }}, \mathrm{p} 27^{\mathrm{Kip} 1}$, and $\mathrm{p} 57^{\mathrm{Kip} 2}$ encoded by CDKN1A, CDKN1B, and $C D K N 1 C$, respectively; and the phosphatases $\mathrm{Cdc} 25 \mathrm{a}$ and $\mathrm{Cdc} 25 \mathrm{c}$ encoded by $C D C 25 A$ and $C D C 25 C$, respectively. Furthermore, we analyzed the mRNA levels of the tumor suppressor TP53 and gene kinesin target of monastrol (EG5). The levels of $G A D D 45 A$, a DNA damage indicator gene, and proapoptotic (BAX and $B A K)$ and anti-apoptotic (SURVIVIN, $B C L-2$, and $B C L-X L)$ genes were also investigated. The data were normalized using the constitutively expressed glyceraldehyde-3-phosphate dehydrogenase $(G A P D H)$ gene, and three biological experiments were performed in duplicate. The sequences of the primers are shown in Table S1 (Supplementary data).

\section{Statistical analysis}

The data obtained in the cytotoxicity assay, flow cytometry to assess induction of apoptosis and cell cycle phase, evaluation of apoptosis in situ, and mitotic index were analyzed using analysis of variance (ANOVA) followed by Dunnett's test $(p<0.05)$ using GraphPad Prism $® 5$ software. Gene expression was analyzed with relative quantification, using GAPDH as a reference gene, according to Pfaffl with REST $\odot$ software (Relative Expression Software Tool; Pfaffl et al. 2002). To filter out unreliable data and to identify genes with significantly different expression, a standard 2-fold change in expression was used as the cut-off point. The efficiencies were estimate by LinRegPCR software. 


\section{Results}

\section{MTT cytotoxicity assay}

The MTT assay revealed that only the breast adenocarcinoma cell line (MCF-7) showed cytotoxicity when exposed to monastrol. MCF-7 cells had a significantly reduced viability near $25 \%$ when treated with monastrol at concentrations of 50,75 , and $100 \mu \mathrm{M}$ for $24 \mathrm{~h}$ (cell viability percentage of 74.5, 76.5, and 77.8, respectively) (Fig. 1a). After $48 \mathrm{~h}$ of exposure, cell viability was significantly reduced near $40 \%$ at the same concentrations (cell viability percentage of 60.3, 55.3, and 57.3, respectively) (Fig. 1b). HB4a cells showed no significant cytotoxicity in response to any of the tested concentrations (Fig. 1).

\section{RTCA assay}

HB4a and MCF-7 cells showed two distinct patterns of proliferation curves in RTCA after treatment with monastrol for long periods with continuous readings at short intervals. MCF-7 cells showed an initial decrease in normalized cell index (NCI) after exposure to higher monastrol concentrations
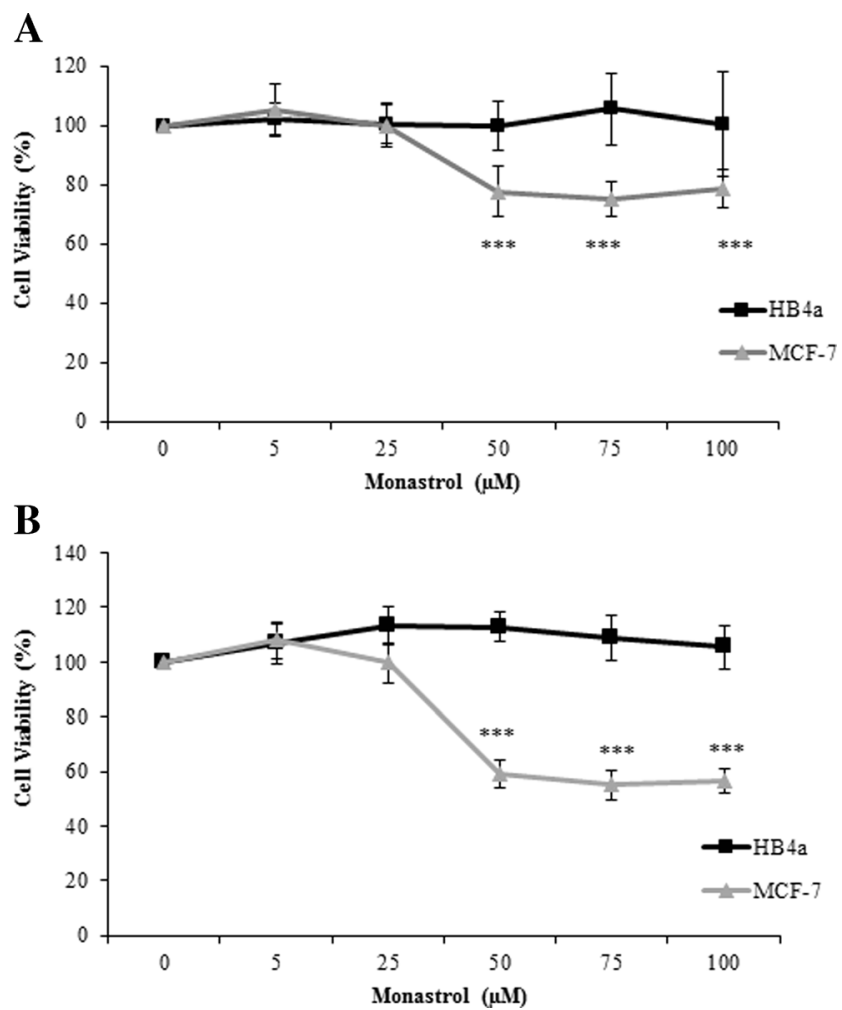

Fig. 1 Cytotoxicity in MCF-7 and HB4a cells after exposure to monastrol. Cell viability (\%) obtained by MTT assay from the treatment of MCF-7 and HB4a cells with monastrol 0 (control), 5, 25, 50, 75, and $100 \mu \mathrm{M}$ for 24 (a) and $48 \mathrm{~h}(\mathbf{b})$. The points represent mean values of cell viability \pm standard deviation obtained in three independent experiments. $* * * p<0.001$ relative to control using ANOVA followed by Dunnett's test
$(50,75$, and $100 \mu \mathrm{M})$, with a maximum decrease after approximately $24 \mathrm{~h}$. After approximately $30 \mathrm{~h}$, there was a subsequent recovery of the proliferation of cells exposed to monastrol (50 and $75 \mu \mathrm{M})$. However, the NCI of treated cells did not return to the NCI of the controls. MCF-7 cells exposed to $100 \mu \mathrm{M}$ monastrol did not return to exponential growth (Fig. 2). In HB4a cells, only $100 \mu \mathrm{M}$ monastrol induced a linear decrease in the CI during the treatment period (Fig. 3). After $48 \mathrm{~h}$ of exposure to $75 \mu \mathrm{M}$ monastrol, HB4a cells initiated a proliferation decrease relative to control. Based on these results, the monastrol concentrations chosen for subsequent experiments were 25 and $50 \mu \mathrm{M}$.

\section{Hoechst 33342 staining: apoptosis and mitotic index}

Analysis of the mitotic index by Hoechst 33342 staining was performed to distinguish cell cycle arrest in the mitotic phase. MCF-7 cells showed a significant increase in mitotic index of 4.7- and 2.4-fold compared with control when exposed to $50 \mu \mathrm{M}$ of monastrol for 24 and $48 \mathrm{~h}$, respectively (Fig. 4a). At the same concentration of monastrol, HB4a cells had a significant increase of 2.7- and 2-fold compared with controls at 24 and $48 \mathrm{~h}$ of exposure, respectively (Fig. 4b). Consistently, the photomicrographs showed an increase of cells in mitotic division with stained and surrounded chromosomes (Fig. 4c). At a low concentration of monastrol (25 $\mu \mathrm{M})$, no significant changes were found in either cell line tested (Fig. 4). In the morphological analysis with Hoechst 33342 staining, the cells exposed to monastrol for any time tested did not demonstrate an increase in apoptosis.

\section{Cell cycle flow cytometry}

The results obtained from assessment of the cell cycle by flow cytometry and mitotic index indicate that the MCF-7 cells are more sensitive to monastrol than HB4a cells. The analysis of the cell cycle distribution of MCF-7 cells demonstrates that within $24 \mathrm{~h}$ of exposure to $50 \mu \mathrm{M}$ monastrol, the cells had a significant increase in the frequency $(\%)$ of cells in G1 and $\mathrm{G} 2 / \mathrm{M}$ phases. The increase in $\mathrm{G} 1$ and $\mathrm{G} 2 / \mathrm{M}$ phases was accompanied by a decrease in the frequency of cells in the $\mathrm{S}$ phase. Cells exposed to $25 \mu \mathrm{M}$ monastrol showed a significant increase only in the G1 phase (Fig. 5a). Within $48 \mathrm{~h}$ of exposure to monastrol $(50 \mu \mathrm{M})$, the cell population showed a similar pattern of behavior with a significant reduction in the population of cells in the $\mathrm{S}$ phase and a significant increase in those in G2/M phase relative to control. The exposure of the cells to $25 \mu \mathrm{M}$ of monastrol for $48 \mathrm{~h}$ caused a significant increase in cells in the G1 phase and a significant decrease in cells in the $\mathrm{G} 2 / \mathrm{M}$ phases (Fig. 5b).

The analysis of HB4a cells demonstrates that only a concentration of $50 \mu \mathrm{M}$ monastrol caused changes in cell cycle dynamics. After $24 \mathrm{~h}$, there was a significant increase in the 
Fig. 2 Real-time cell growth kinetics of MCF-7 cells exposed to monastrol. Cell index curves of the MCF-7 cells obtained by xCELLigence-RTCA system showing the kinetics of cell growth following exposure to monastrol for $96 \mathrm{~h}$. The normalized cell index (NCI) was measured every $30 \mathrm{~min}$, and the points represent mean NCI values obtained in triplicate

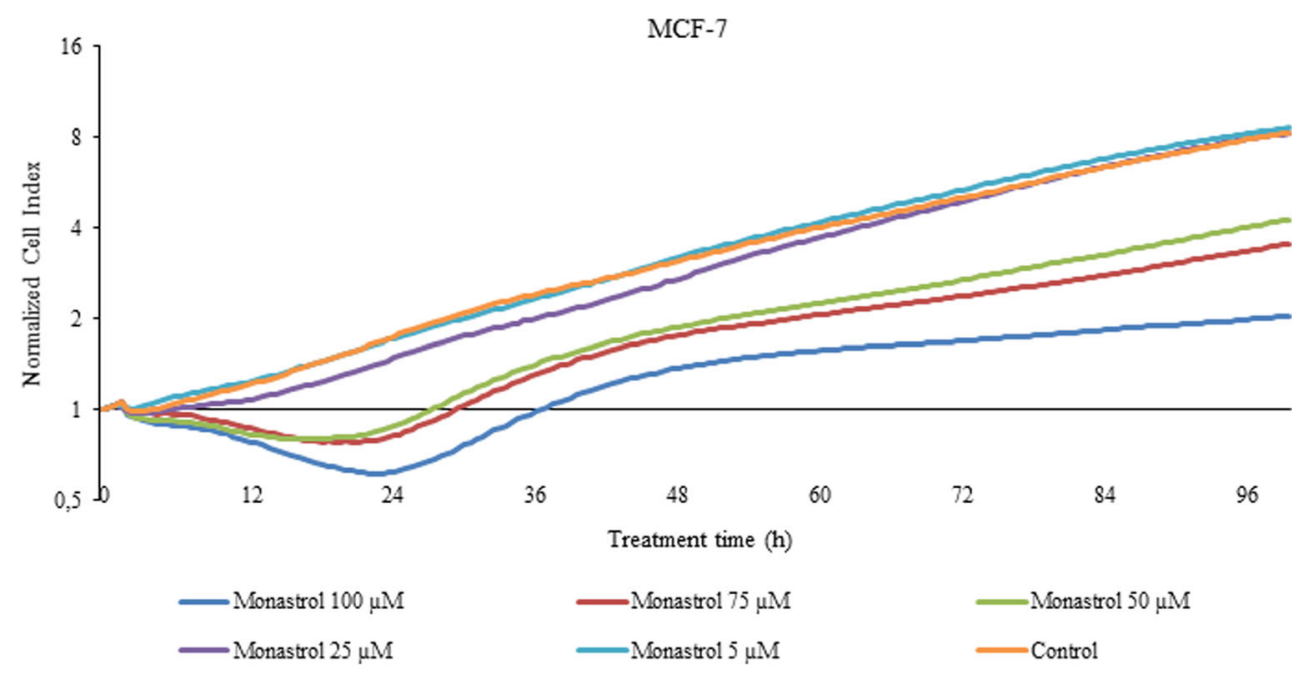

G2/M population and a significant decrease in the frequency of G1 (Fig. 6a). After $48 \mathrm{~h}$ of exposure, all phases of the cell cycle were changed significantly when exposed to $50 \mu \mathrm{M}$ monastrol, with a decrease of cells in the G1 and S phases and an increase in those in the G2/M phase (Fig. 6b).

\section{Apoptosis flow cytometry}

To investigate the mechanism that leads to reduced cell viability and alterations in the kinetics of cell growth, an analysis of apoptosis was performed. The apoptosis analysis with Annexin V by flow cytometry, as well as in the cell cycle analysis of the sub-G1 population (data not shown), showed no significant induction of apoptosis (Fig. 7).

\section{RT-qPCR}

The gene expression of cell cycle components, such as cyclins, inhibitors of CDK, phosphatases, and the kinesin
$E G 5$, as well as genes involved in apoptosis and DNA damage response were evaluated. MCF-7 cells showed a significant increase in mRNA levels of the CDK inhibitor CDKN1A (5fold change) after exposure to monastrol (Fig. 8). The nontumoral HB4a cells showed a significant decrease in mRNA levels of CDKN1C (2-fold change) (Fig. 8). The expression levels of the other genes were unchanged compared with the controls (Fig. 9).

\section{Discussion}

The antiproliferative activity of monastrol has been related (Chin and Herbst 2006; Kaur et al. 2010; Leizerman et al. 2004; Russowsky et al. 2006; Vijapurkar et al. 2007); however, the molecular mechanism and the role of monastrol in tumor cells compared with non-tumor cells are poorly known. In this study, we investigate the effects of this compound on the breast tumor MCF-7 cell line and the non-tumor mammary
Fig. 3 Real-time cell growth kinetics of HB4a cells exposed to monastrol. Cell index curves of the HB4a cells obtained by xCELLigence-RTCA system showing the kinetics of cell growth following exposure to monastrol for $96 \mathrm{~h}$. The normalized cell index (NCI) was measured every $30 \mathrm{~min}$, and the points represent mean NCI values obtained in triplicate

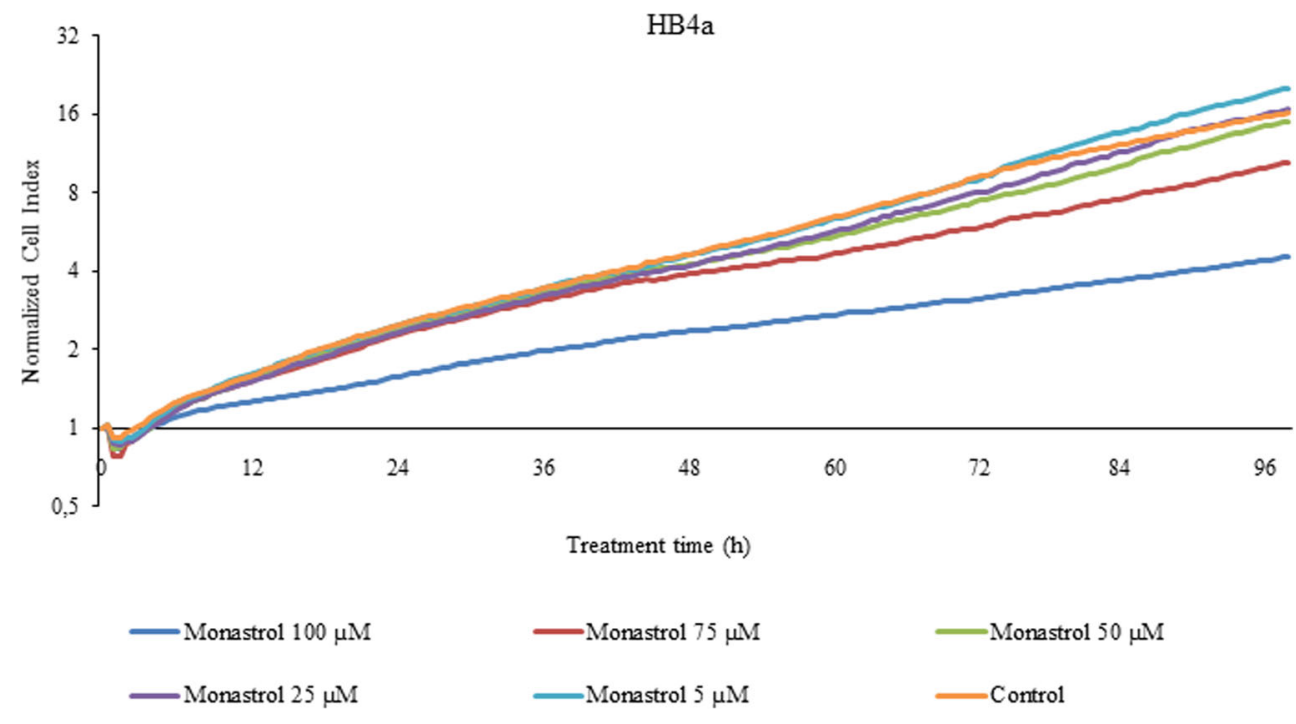


Fig. 4 Monastrol causes an increase in mitotic index of MCF7 and HB4a cells. Mitotic index by staining with Hoechst 33342 in MCF-7 (a) and HB4a (b) cells treated for 24 and $48 \mathrm{~h}$ with monastrol. c Photomicrographs showing morphology by staining with Hoechst 33342. Data are presented as the mean \pm standard deviation of three independent experiments. $* p<0.05$,

$* * p<0.01, * * * p<0.001$ relative to control using ANOVA followed by Dunnett's test. Arrows indicate arrest cells in mitosis and arrowhead indicates apoptotic cell (magnification $\times 460$ )
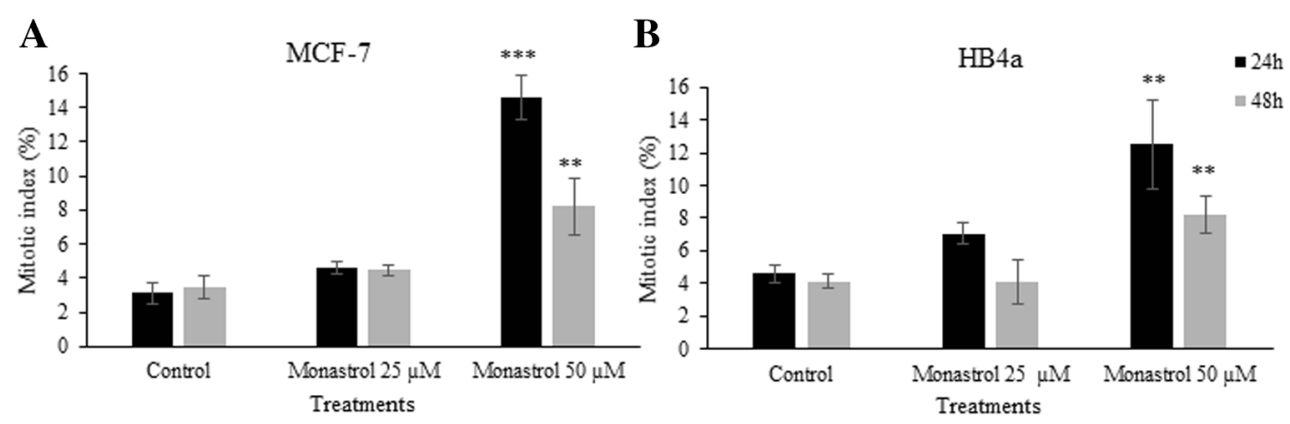

C
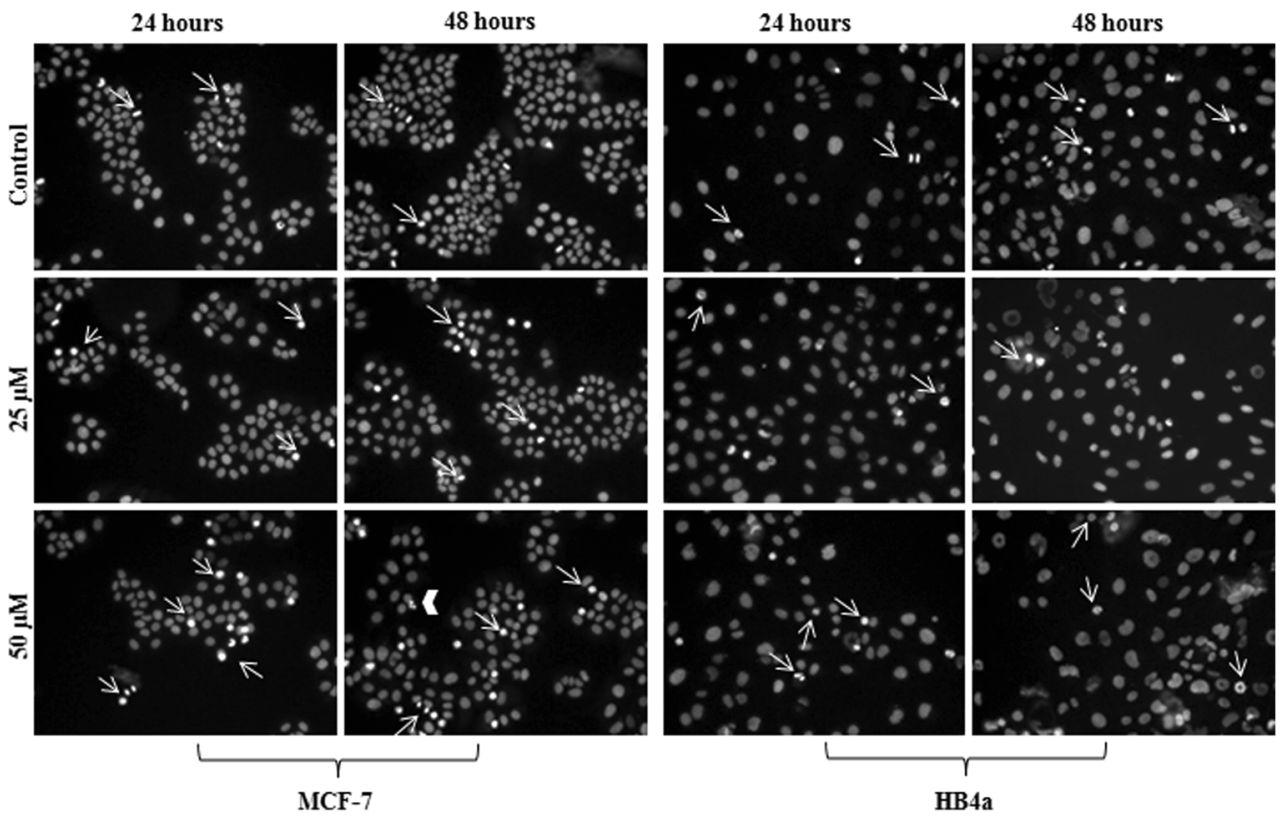

HB4a
HB4a cell line, and we found that monastrol has a more pronounced cytotoxic and antiproliferative activity to tumoral cells when compared with non-tumoral cells. It was observed that monastrol causes cell cycle arrest in the G2/M and G1 phases and there is an evident increase in mRNA levels of the cyclin-kinase inhibitor CDKN1A on MCF-7 cells. For the non-tumor $\mathrm{HB} 4 \mathrm{a}$ cell line, although exposure to monastrol causes cell cycle arrest at the G2/M phase, the observed effects were generally more discreet.

Both MTT cytotoxicity assay and real-time cell growth kinetics showed that monastrol exhibited a more pronounced cytotoxic and antiproliferative activity to MCF-7 cells than to HB4a cells. In MTT cytotoxicity assay, only the MCF-7 tumor cells showed a reduction of viability after exposure to this compound. Also, in the analysis of real-time cell growth kinetics, it was possible to observe that $\mathrm{MCF}-7$ cells were more sensible than HB4a cells to monastrol antiproliferative activity.

The analysis of the cytotoxicity profiles by real-time cell analyzer can provide important information about its mechanism of action according to the time-dependent cell response profiles (TCRPs). Abassi et al. (2009) showed that molecules with similar mechanisms of action had similar TCRPs. In the present study, MCF-7 cells presented a decrease in normalized cell index (NCI) after exposure to monastrol with a subsequent recovery of the proliferation after approximately $30 \mathrm{~h}$. This response resembles the profile presented by antimitotic agents (paclitaxel, colchicine, and nocadazol) and by lung carcinoma cells (A549) exposed to monastrol (Abassi et al. 2009). The authors suggested that the initial decline in NCI is correlated with morphological changes resulting from arrest in mitosis, such as cell rounding and detachment of the cells, and recovery of the NCI was attributed to the subpopulation of cells that escape mitosis and large cells that failed cytokinesis (Abassi et al. 2009). The HB4a cells continued their exponential growth similar to the control group, and only a concentration of $100 \mu \mathrm{M}$ monastrol altered the growth kinetics early $(<12 \mathrm{~h})$.

Some reports have shown that monastrol prevents the formation of the bipolar mitotic spindle by retaining cells in G2/ $\mathrm{M}$ through the activation of the spindle checkpoint by binding to the kinesin Eg5 (Chin and Herbst 2006; DeBonis et al. 2003; Haque et al. 2004; Kapoor et al. 2000; Leizerman et al. 2004; Maliga et al. 2002; Mayer et al. 1999; 
A

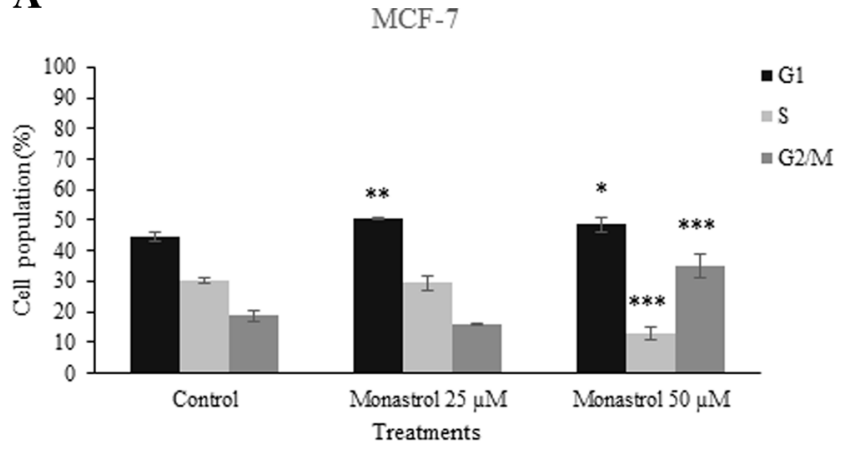

B

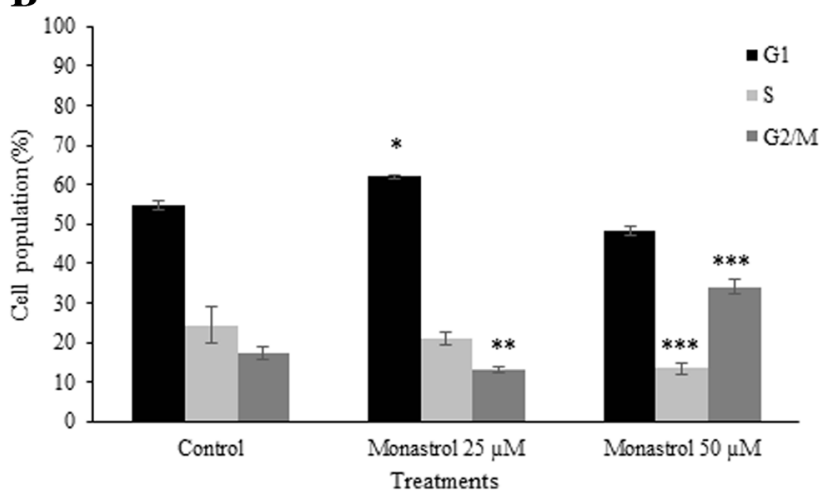

Fig. 5 Analysis of the population distribution of MCF-7 cells in the cell cycle by flow cytometry. Effects of treatment with 25 and $50 \mu \mathrm{M}$ monastrol on the distribution of the cell cycle (G1, S, G2/M) after $24 \mathrm{~h}$ (a) and $48 \mathrm{~h}$ (b) of treatment. Data are presented as the mean \pm standard deviation of three independent experiments. ${ }^{*} p<0.05$, ${ }^{*} p<0.01$, $* * * p<0.001$ relative to control using ANOVA followed by Dunnett's test

Vijapurkar et al. 2007). Therefore, to investigate the mechanisms by which monastrol inhibits cell growth, the cell cycle dynamic by flow cytometry was performed. Our results show that monastrol altered the profile of normal distribution of MCF-7 cells in the cell cycle, with a drastic increase in the population in $\mathrm{G} 2 / \mathrm{M}$ and increase in mitotic index, suggesting that blocking has occurred in the $\mathrm{M}$ phase (mitosis) of the cycle. However, after $48 \mathrm{~h}$ of exposure, there was a reduction in the mitotic index without a decrease of cells with DNA content $4 \mathrm{n}$. This suggests that a proportion of the cells retained in $\mathrm{M}$ phase after $24 \mathrm{~h}$ of exposure exited mitosis without dividing their genetic material, probably due to mitotic slippage, and formed a population of cells with $4 \mathrm{n}$ DNA content retained in the G1-like state phase by a mechanism known as adaptation (Gascoigne and Taylor 2008; Rieder and Maiato 2004; Weaver and Cleveland 2005). In HB4a cells, this effect is also found but in smaller proportions. Similar results were obtained by Asraf et al. (2015) after exposing five different cell lines (AGS, HepG2, LoVo, Du145, and HT29) to monastrol $(20-150 \mu \mathrm{M})$. They found that all cell lines showed an increase in the population of cells with 4 n DNA content, with two phenotypes based on sensitivity to monastrol and levels of survivin: cells in mitotic arrest or a G1-like state. In the current study, levels of SURVIVIN mRNA were not altered
A

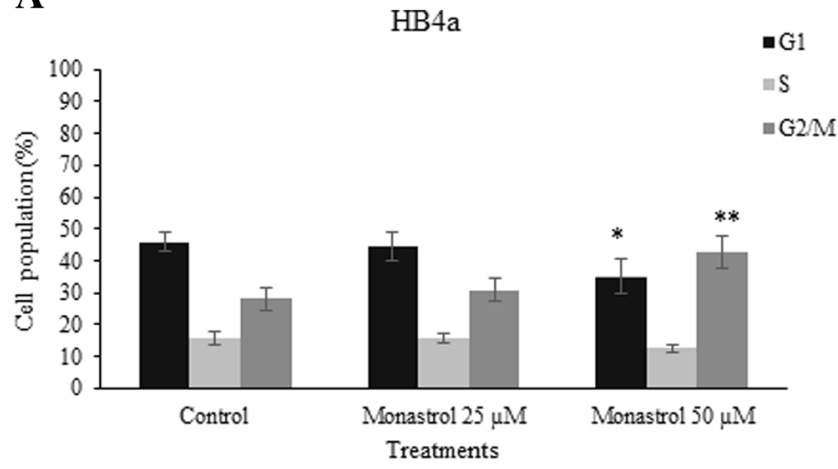

B

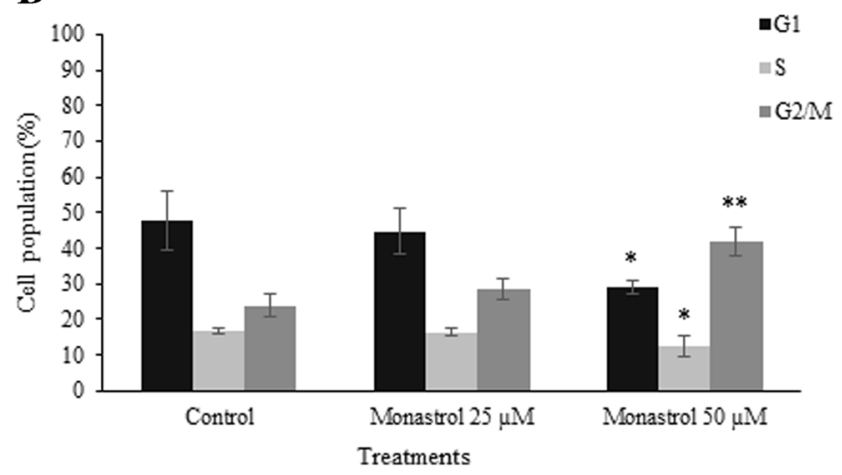

Fig. 6 Analysis of the population distribution of HB4a cells in the cell cycle by flow cytometry. Effects of treatment with 25 and $50 \mu \mathrm{M}$ monastrol in the distribution of the cell cycle $(\mathrm{G} 1, \mathrm{~S}, \mathrm{G} 2 / \mathrm{M})$ after $24 \mathrm{~h}$ (a) and $48 \mathrm{~h}$ (b) of treatment. Data are presented as the mean \pm standard deviation of three independent experiments. ${ }^{*} p<0.05$, ${ }^{* *} p<0.01$, $* * * p<0.001$ relative to control using ANOVA followed by Dunnett's test

in the presence of monastrol in either cell line, and some cells remained in a G1-like state, suggesting sensitivity of these cells to monastrol.

The cell cycle is regulated by the CDKs, which, among other modes of regulation, can be activated by cyclins and inactivated by their inhibitors, the CKIs. The overexpression of $\mathrm{p} 57^{\mathrm{Kip} 2}$ is related to arrest at the G1 phase of the cell cycle through inhibition of the complex of $\mathrm{CDK} /$ cyclin (Kavanagh and Joseph 2011; Ullah et al. 2008). p5 $7^{\text {Kip2 }}$ is a candidate tumor suppressor, and its downregulation or absence can influence breast tumorigenesis (Larson et al. 2008; Xu et al. 2012). In the present study, CDKNIC expression levels were decreased in the HB4a cells when exposed to monastrol. Such downregulation may be correlated with the observed decrease in the G1 population. The increase of the G2/M population may be due to monastrol activity and activation of the spindle checkpoint.

MCF-7 cells exposed to monastrol had a 5-fold increase in expression levels of the CDKN1A gene. CDKN1A gene encodes the protein $\mathrm{p} 21^{\mathrm{Cip} / \mathrm{Waf} 1 / \mathrm{Sdi} 1}$ and is a transcriptional target of the $\mathrm{p} 53$ tumor suppressor protein. Stresses suffered by the cell, such as DNA damage, can increase the levels of $\mathrm{p} 21^{\mathrm{Cip} /}$ Wafl/Sdil (Green and Kroemer 2009). This protein, as well as other family members, is an inhibitor of CDKs (Sherr and 
A

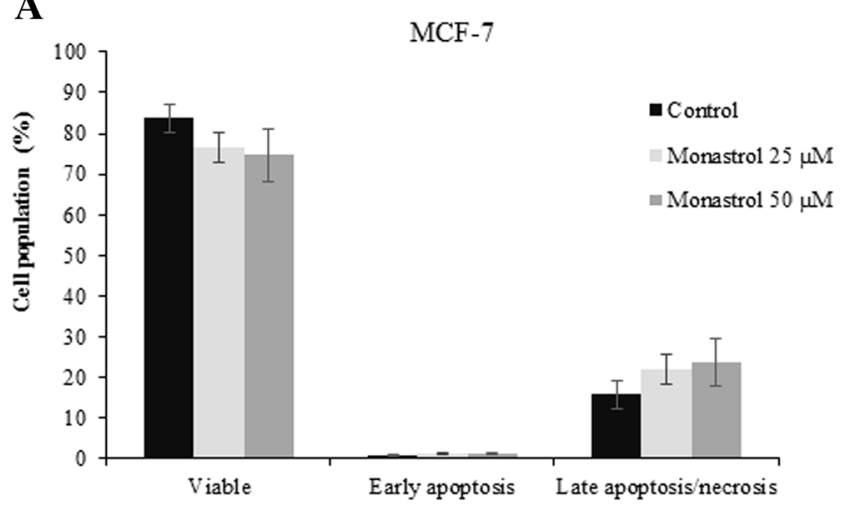

B

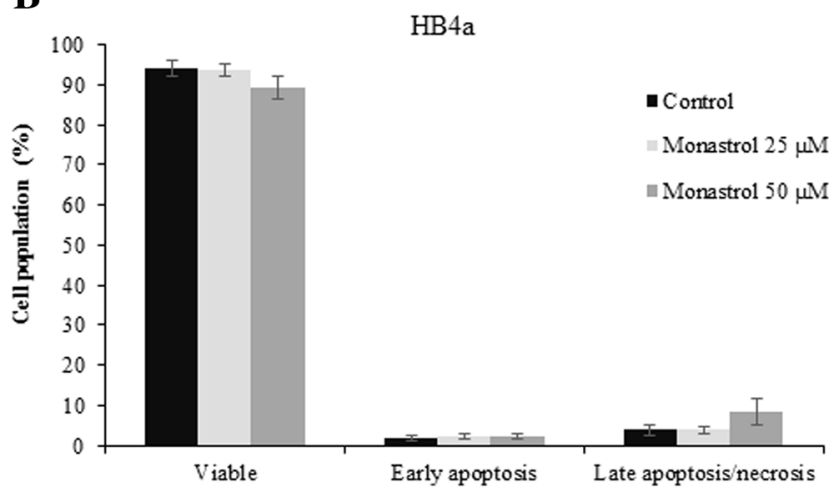

Fig. 7 Monastrol does not induce apoptosis in MCF-7 and HB4a cells. The cells were exposed to 25 and $50 \mu \mathrm{M}$ of monastrol for $24 \mathrm{~h}$, stained with Annexin V/PE and 7AAD for MCF-7 (a) and Annexin V/FITC and $P I$ for HB4a cells (b) to obtain the percentage of apoptotic cells by flow cytometry. Data are presented as the mean \pm standard deviation of three independent experiments $(p<0.05)$

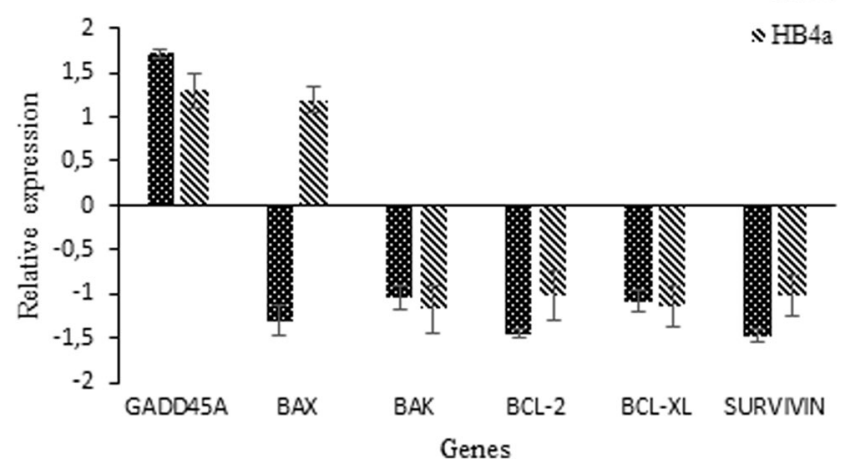

Fig. 9 Relative expression of genes related to DNA damage (GADD45A) and apoptosis (BAX, BAK, SURVIVIN, BCL-2, and BCL$X L$ ) obtained by RT-qPCR after $24 \mathrm{~h}$ of treatment with $50 \mu \mathrm{M}$ monastrol. The relative expression of each target gene was normalized with the reference genes glyceraldehyde 3-phosphate dehydrogenase (GAPDH). The data are presented as the mean of the relative expression of three independent experiments with mechanical duplicates. Statistical analyses were calculated by REST 2009 software with expression sieve $\geq 2$ or $\leq-2$. *Significant with $p \leq 0.05$

Roberts 1999). Therefore, the upregulation of CDKN1A can be correlated with cell cycle inhibition in the G1 phase (Sherr and Roberts 1999) and G2/M (Abbas and Dutta 2009; Mandal et al. 1998), agreeing with the data observed in our study. Other studies with HCT116 and RPE1 cells exposed to monastrol demonstrated an increase in chromosome missegregation with cell cycle arrest and accumulation of p21 without DNA damage (Thompson and Compton 2008, 2010). Cells that survive the arrest in G2/M and that have high

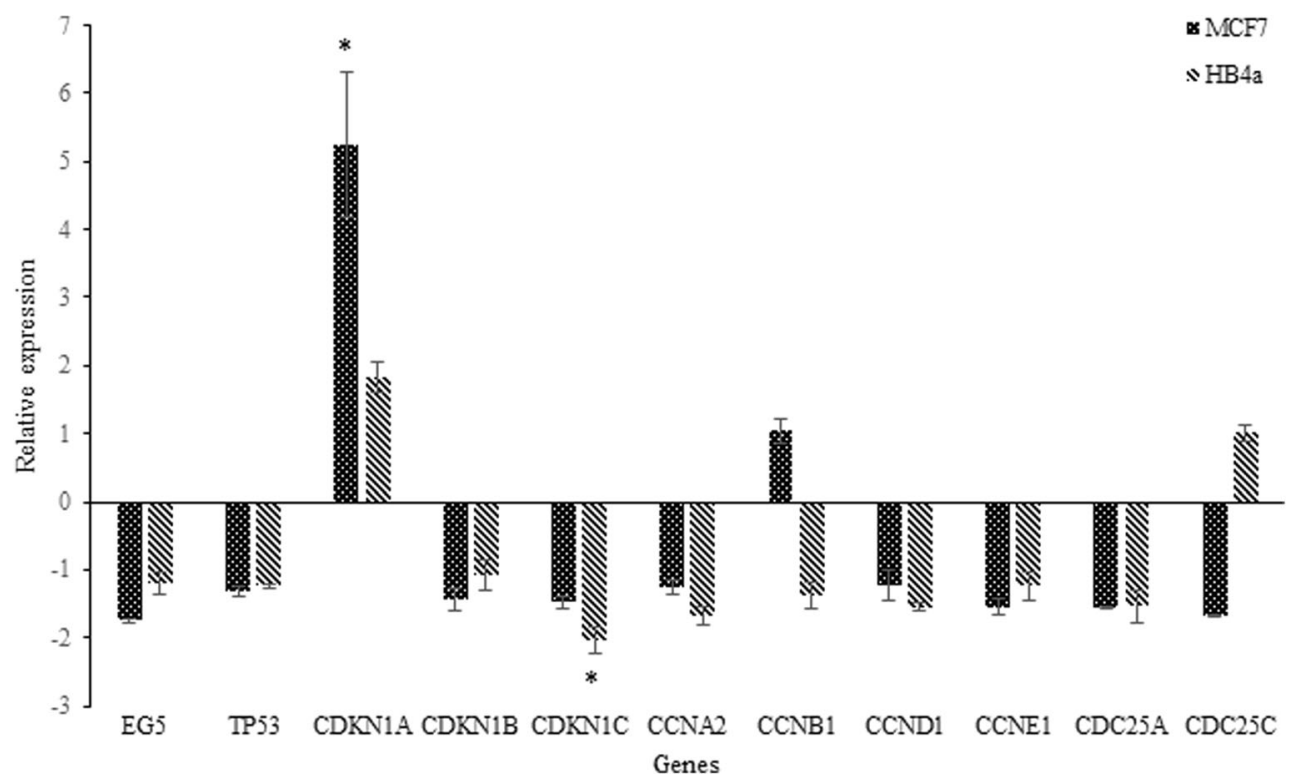

Fig. 8 Relative expression of genes related to cell cycle. Levels of transcripts of EG5, TP53, CDKN1A, CDKN1B, CDKN1C, CCNA2, $C C N B 1, C C N D 1, C C N E 1, C D C 25 A$, and $C D C 25 C$ genes obtained by RT-qPCR after $24 \mathrm{~h}$ treatment with $50 \mu \mathrm{M}$ monastrol. The relative expression of each target gene was normalized with the reference genes

glyceraldehyde 3-phosphate dehydrogenase $(G A P D H)$. The data are presented as the mean of the relative expression of three independent experiments with mechanical duplicates. Statistical analyses were calculated by REST 2009 software with expression sieve $\geq 2$ or $\leq-2$. *Significant with $p \leq 0.05$ 
levels of $\mathrm{p} 21^{\mathrm{Cip} / \mathrm{Waf} 1 / \mathrm{Sdi1}}$ can be retained in G1 phase, can proceed to cell death, undergo endoreplication, continue in the cycle, or even become senescent. It has been reported that high expressions of $\mathrm{p} 21^{\mathrm{Cip} / \mathrm{Waf} 1 / \mathrm{Sdil}}$ can suppress mammary carcinoma cell growth (Shibata et al. 2001), and its absence is an indicator of poor prognosis for cancer (Abukhdeir and Park 2008).

In all parameters of assessment, we found that monastrol was not able to promote apoptosis of the HB4a and MCF7 cells. Costa-Rosa (2011) verified that treatment of MCF-7 cells with monastrol $(100 \mu \mathrm{M})$ also resulted in an increase in the $\mathrm{G} 2 / \mathrm{M}$ population without inducing programmed cell death. Similar results were found for lung carcinoma line A549 (Vijapurkar et al. 2007). In contrast, other studies have found an induction of apoptosis in gastric adenocarcinoma cells (AGS) and colorectal (HT-29) (Leizerman et al. 2004), cervix carcinoma (HeLa) (Chin and Herbst 2006), and melanoma cells (UACC62) (Russowsky et al. 2006) exposed to monastrol.

\section{Conclusion}

In summary, our results indicate that monastrol exerts differential antiproliferative activity towards breast adenocarcinoma MCF-7 cells and mammary epithelium HB4a cells. In all parameters evaluated, monastrol was less effective to non-tumor HB4a cells than to MCF-7 cells. The antiproliferative activity of this compound to MCF-7 cells is related to arrest in the M phase of the cell cycle with characteristics that suggest mitotic slippage. At low doses of monastrol, MCF-7 cells were arrested in the G1 phase of the cell cycle. The cell cycle inhibition of MCF-7 cells was mediated by an accentuated upregulation of CDKN1A mRNA levels. For the non-tumor HB4a cell line, although exposure to monastrol causes cell cycle arrest at the G2/M phase, the observed effects were generally more discreet. Thus, this study provides evidence that MCF-7 and HB4a cells have different sensitivities to monastrol, which has a greater antiproliferative effect on tumor cells; however, no selective is observed.

Acknowledgments This research was support by CNPq, CAPES, and Fundação Araucária, Brazil.

\section{References}

Abassi YA, Xi B, Zhang W, et al. (2009) Kinetic cell-based morphological screening: prediction of mechanism of compound action and off-target effects. Chem Biol 16:712-723. doi:10.1016/j. chembiol.2009.05.011

Abbas T, Dutta A (2009) p21 in cancer: intricate networks and multiple activities. Nat Rev Cancer 9:400-414. doi:10.1038/nrc2657
Abukhdeir AM, Park BH (2008) P21 and p27: roles in carcinogenesis and drug resistance. Expert Rev Mol Med 10:e19. doi:10.1017 /S1462399408000744

Asraf H, Amsterdam A, Ben-Menahem D (2015) Modulation of the steroidogenic related activity according to the design of single-chain bovine FSH analogs. Gen Comp Endocrinol 216:171-181. doi:10.1016/j.ygcen.2015.04.004

Blangy A, Lane HA, d'Herin P, et al. (1995) Phosphorylation by p34cdc2 regulates spindle association of human Eg5, a kinesin-related motor essential for bipolar spindle formation in vivo. Cell 83:1159-1169

Chin GM, Herbst R (2006) Induction of apoptosis by monastrol, an inhibitor of the mitotic kinesin Eg5, is independent of the spindle checkpoint. Mol Cancer Ther 5:2580-2591. doi:10.1158/15357163.MCT-06-0201

Costa-Rosa Md (2011) Interferindo na progressão do ciclo celular para avaliar possíveis alterções de ploidia em células tumorais de mam humana. Universidade de São Paulo

DeBonis S, Simorre JP, Crevel I, et al. (2003) Interaction of the mitotic inhibitor monastrol with human kinesin Eg5. Biochemistry 42:338349. doi:10.1021/bi026716j

Enos AP, Morris NR (1990) Mutation of a gene that encodes a kinesinlike protein blocks nuclear division in A. nidulans. Cell 60:10191027

Ferenz NP, Gable A, Wadsworth P (2010) Mitotic functions of kinesin-5. Semin Cell Dev Biol 21:255-259. doi:10.1016/j. semcdb.2010.01.019

Ferlay J, Soerjomataram I, Dikshit R, et al. (2015) Cancer incidence and mortality worldwide: sources, methods and major patterns in GLOBOCAN 2012. Int J Cancer 136:E359-E386. doi:10.1002 /ijc. 29210

Gascoigne KE, Taylor SS (2008) Cancer cells display profound intra- and interline variation following prolonged exposure to antimitotic drugs. Cancer Cell 14:111-122. doi:10.1016/j.ccr.2008.07.002

Green DR, Kroemer G (2009) Cytoplasmic functions of the tumour suppressor p53. Nature 458:1127-1130. doi:10.1038/nature07986

Hanahan D, Weinberg RA (2000) The hallmarks of cancer. Cell 100:5770

Hanahan D, Weinberg RA (2011) Hallmarks of cancer: the next generation. Cell 144:646-674. doi:10.1016/j.cell.2011.02.013

Haque SA, Hasaka TP, Brooks AD, et al. (2004) Monastrol, a prototype anti-cancer drug that inhibits a mitotic kinesin, induces rapid bursts of axonal outgrowth from cultured postmitotic neurons. Cell Motil Cytoskeleton 58:10-16. doi:10.1002/cm.10176

Harrison MR, Holen KD, Liu G (2009) Beyond taxanes: a review of novel agents that target mitotic tubulin and microtubules, kinases, and kinesins. Clin Adv Hematol Oncol 7:54-64

Huszar D, Theoclitou ME, Skolnik J, Herbst R (2009) Kinesin motor proteins as targets for cancer therapy. Cancer Metastasis Rev 28: 197-208. doi:10.1007/s10555-009-9185-8

Kapoor TM, Mayer TU, Coughlin ML, Mitchison TJ (2000) Probing spindle assembly mechanisms with monastrol, a small molecule inhibitor of the mitotic kinesin, Eg5. J Cell Biol 150:975-988

Kaur J, Sundar S, Singh N (2010) Molecular docking, structure-activity relationship and biological evaluation of the anticancer drug monastrol as a pteridine reductase inhibitor in a clinical isolate of Leishmania donovani. J Antimicrob Chemother 65:1742-1748. doi:10.1093/jac/dkq189

Kavanagh E, Joseph B (2011) The hallmarks of CDKN1C (p57, KIP2) in cancer. Biochim Biophys Acta 1816:50-56. doi:10.1016/j. bbcan.2011.03.002

Koller E, Propp S, Zhang H, et al. (2006) Use of a chemically modified antisense oligonucleotide library to identify and validate Eg5 (kinesin-like 1) as a target for antineoplastic drug development. Cancer Res 66:2059-2066. doi:10.1158/0008-5472.CAN-05-1531 
Larson PS, Schlechter BL, King CL, et al. (2008) CDKN1C/p57kip2 is a candidate tumor suppressor gene in human breast cancer. BMC Cancer 8:68. doi:10.1186/1471-2407-8-68

Le Guellec R, Paris J, Couturier A, et al. (1991) Cloning by differential screening of a Xenopus cDNA that encodes a kinesin-related protein. Mol Cell Biol 11:3395-3398

Leizerman I, Avunie-Masala R, Elkabets M, et al. (2004) Differential effects of monastrol in two human cell lines. Cell Mol Life Sci 61: 2060-2070. doi:10.1007/s00018-004-4074-3

Lin S, Liu M, Son YJ, et al. (2011) Inhibition of Kinesin-5, a microtubulebased motor protein, as a strategy for enhancing regeneration of adult axons. Traffic 12:269-286. doi:10.1111/j.16000854.2010.01152.x

Maliga Z, Mitchison TJ (2006) Small-molecule and mutational analysis of allosteric Eg5 inhibition by monastrol. BMC Chem Biol 6:2. doi:10.1186/1472-6769-6-2

Maliga Z, Kapoor TM, Mitchison TJ (2002) Evidence that monastrol is an allosteric inhibitor of the mitotic kinesin Eg5. Chem Biol 9:989 996

Mandal M, Bandyopadhyay D, Goepfert TM, Kumar R (1998) Interferon-induces expression of cyclin-dependent kinase-inhibitors p21WAF1 and p27Kip1 that prevent activation of cyclin-dependent kinase by CDK-activating kinase (CAK. Oncogene 16:217-225. doi:10.1038/sj.onc.1201529

Mayer TU, Kapoor TM, Haggarty SJ, et al. (1999) Small molecule inhibitor of mitotic spindle bipolarity identified in a phenotype-based screen. Science 286:971-974

Mosmann T (1983) Rapid colorimetric assay for cellular growth and survival: application to proliferation and cytotoxicity assays. $\mathrm{J}$ Immunol Methods 65:55-63

Pfaffl MW, Horgan GW, Dempfle L (2002) Relative expression software tool (REST) for group-wise comparison and statistical analysis of relative expression results in real-time PCR. Nucleic Acids Res 30: e36

Rieder CL, Maiato H (2004) Stuck in division or passing through: what happens when cells cannot satisfy the spindle assembly checkpoint. Dev Cell 7:637-651. doi:10.1016/j.devcel.2004.09.002

Rowinsky EK, Chaudhry V, Cornblath DR, Donehower RC (1993) Neurotoxicity of Taxol. J Natl Cancer Inst Monogr:107-115

Russowsky D, Canto RF, Sanches SA, et al. (2006) Synthesis and differential antiproliferative activity of Biginelli compounds against cancer cell lines: monastrol, oxo-monastrol and oxygenated analogues. Bioorg Chem 34:173-182. doi:10.1016/j.bioorg.2006.04.003
Sakowicz R, Finer JT, Beraud C, et al. (2004) Antitumor activity of a kinesin inhibitor. Cancer Res 64:3276-3280

Savio AL, da Silva GN, de Camargo EA, Salvadori DM (2014) Cell cycle kinetics, apoptosis rates, DNA damage and TP53 gene expression in bladder cancer cells treated with allyl isothiocyanate (mustard essential oil. Mutat Res Fundam Mol Mech Mutagen 762:40-46. doi:10.1016/j.mrfmmm.2014.02.006

Sherr CJ, Roberts JM (1999) CDK inhibitors: positive and negative regulators of G1-phase progression. Genes Dev 13:1501-1512

Shibata MA, Yoshidome K, Shibata E, et al. (2001) Suppression of mammary carcinoma growth in vitro and in vivo by inducible expression of the Cdk inhibitor p21. Cancer Gene Ther 8:23-35. doi:10.1038 /sj.cgt. 7700275

Thompson SL, Compton DA (2008) Examining the link between chromosomal instability and aneuploidy in human cells. J Cell Biol 180: 665-672. doi:10.1083/jcb.200712029

Thompson SL, Compton DA (2010) Proliferation of aneuploid human cells is limited by a p53-dependent mechanism. J Cell Biol 188:369 381. doi:10.1083/jcb.200905057

Tuxen MK, Hansen SW (1994) Neurotoxicity secondary to antineoplastic drugs. Cancer Treat Rev 20:191-214

Ullah Z, Kohn MJ, Yagi R, et al. (2008) Differentiation of trophoblast stem cells into giant cells is triggered by $\mathrm{p} 57 / \mathrm{Kip} 2$ inhibition of CDK1 activity. Genes Dev 22:3024-3036. doi:10.1101 /gad.1718108

Vijapurkar U, Wang W, Herbst R (2007) Potentiation of kinesin spindle protein inhibitor-induced cell death by modulation of mitochondrial and death receptor apoptotic pathways. Cancer Res 67:237-245. doi:10.1158/0008-5472.CAN-06-2406

Weaver BA, Cleveland DW (2005) Decoding the links between mitosis, cancer, and chemotherapy: the mitotic checkpoint, adaptation, and cell death. Cancer Cell 8:7-12. doi:10.1016/j.ccr.2005.06.011

Xu XY, Wang WQ, Zhang L, et al. (2012) Clinical implications of p57 KIP2 expression in breast cancer. Asian Pac J Cancer Prev 13:50335036

Xu C, Klaw MC, Lemay MA, et al. (2015) Pharmacologically inhibiting kinesin-5 activity with monastrol promotes axonal regeneration following spinal cord injury. Exp Neurol 263:172-176. doi:10.1016/j. expneurol.2014.10.013

Yoon SY, Choi JE, Huh JW, et al. (2005) Monastrol, a selective inhibitor of the mitotic kinesin Eg5, induces a distinctive growth profile of dendrites and axons in primary cortical neuron cultures. Cell Motil Cytoskeleton 60:181-190. doi:10.1002/cm.20057 